\title{
TESTS OF STATIONARY STEAM BOILERS AT THE CENTENNIAL.
}

The report of Mr. E. M. Hugentobler, expert in charge of the steam boiler tests at the Centennial, to Mr. John S. Albert, Chief of the Bureau of Machinery, is now going through the press, and will cover about 200 octavo pages. It contains all the logs or records of observation, taken with much detail, and otherwise bears evidence of much painstaking in making the tests.

Through the courtesy of Mr. Albert, we have been furnished with a copy of the proof-sheets of the report, from which the following is an extract.

The tables on pages 108 and 109, containing some of the more important results, are compiled from more extended tables, of which there is a separate one for each boiler. In these latter there is also a column of the results of the "Capacity Test" of each boiler, but as the "Economy Test" is of more value to the steam user, only the last need be given here.

K.

Fourteen boilers were tested in the order named: the Wiegand, the Harrison, the Firmenich, the Rogers \& Black, the Andrews, the Root, the Kelly, the Exeter, the Lowe, the Babcock \& Wilcox, the Smith, the Galloway, the Anderson, and the Pierce boilers.

\section{NATURE OF THE TESTS.}

Two tests, each of eight hours' duration, were made of each boiler; the first with full natural draft and clean fires to determine the potential evaporation, the second with fires regulated to burn about threefourths as much coal as before, or, in other words, to approximate average working conditions with a view of ascertaining the economical evaporation.

Calorimeter observations of the quality of the steam were taken at stated intervals during all the tests, and have been taken into account in computing the results of the several trials.

During all the trials a steam-pressure of seventy pounds was regularly maintained on the boilers by adjusting the stop-valves; a steamgauge was attached on the steam-pipe just below the stop-valve, and a man was stationed at all times on top of the boiler to watch the gauge and regulate the valve accordingly.

W tolr No. Vol. CIV.—(Third Series, Vol. 1xxiv.) 
Before beginning an experiment, steam was raised to seventy pounds, when the stop-valve was closed, fires hauled, and ash-pits cleaned. As soon as new fires could be established with weighed wood and coal, the water-level was noted (with fire-doors closed and fires burning), after which the stop-valve was opened; the time of opening the valve being recorded as the time of starting the test. After steaming for eight hours the stop-valve was closed and the water-level again noted (with fire-doors closed); the fires were then hauled and extinguished, and the ash-pits cleaned out.

All the coal and kindling wood, estimated at its equivalent in coal, consumed for starting and maintaining new fires, were charged to the boiler, and all the water pumped into the boiler to maintain the level at the same height was credited to the boiler as evaporated, subject to corrections indicated by calorimeter, as explained below.

In the two tests of the Kelly boiler, the economy trial of the Exeter, and the economy trial of the Babcock \& Wilcox boilers, the level at stopping was higher than at starting; and for those tests the amounts of water corresponding to the differences in level have been deducted from the amounts pumped into those boilers. In all other cases, however, the level at stopping was the same as at starting, or when lower a few strokes of the pump would bring it up to the required point, the water thus pumped being of course credited to the boiler as having been evaporated.

In all cases precautions were taken to trace all connections to the boiler on trial, to see that they were tight; and all blow-off pipes were disconnected, so as to detect any leak that might occur through the blow-off valves. In two or three instances slight leaks occurred, but all the water was collected and deducted from the amount fed into the boiler.

Before starting, the approximate amount of coal needed for the trial was weighed out of the coal-bin and dumped in a separate pile on the floor, away from all other coals. From this pile coal was taken in barrows as required for running the test, and the weight of each barrow-load noted. This plan of keeping two separate accounts of the coal removed all chance of error in the amount of coal actually consumed, as at the close of each experiment the two accounts were balanced, and any error would have been detected at once. The second coal account has been taken as the basis for calculating the evaporation, adding to it, of course, the equivalent of the kindling 
wood, which was taken at the rate of 0.40 pound of coal per pound of wood.

Upon completing a trial, fires were hauled and extinguished as rapidly as possible, the grates and ash-pits carefully cleaned, and all the coal, ashes and clinkers hauled from under the boiler were sifted. The coal was carefully picked by hand and weighed separately. This amount of coal deducted from the amount of coal fired on the grates gives the amount of coal actually consumed. By deducting from the latter the amount of refuse (ashes and clinkers), the amount of combustible consumed was determined.

The feed-water measuring apparatus consisted of two metallic tanks placed on separate platform scales, with provision for filling from the hydrain. A Blake double-plunger feed-pump, supplied with steam from the boiler on trial, was placed between the tanks, and its suction-pipe was provided with a rubber hose, whereby the pump could be made to take water at will from either tank. This pump was used on all the trials, and whenever it was attached to a new boiler, precaution was taken to see that the feed-pipe was tight, and that all other connections of the boiler to other pumps or injectors were broken off.

After filling a tank with water from the hydrant, its gross weight was noted, and after it had been pumped out almost dry, the suctionhose of the pump was shifted to tank No. 2 (previously filled and weighed), and the gross tare of tank No. 1 was taken; the difference between the gross initial weight and the gross tare being the net weight of water pumped into the boiler. Tank No. 1 was then refilled and its gross weight again noted, when it stood ready to supply the pump as soon as tank No. 2 should be emptied.

The temperature of the feed-water was observed twice in each of the tanks. In the logs will be found the gross weights and gross tares of the tank, together with the times at which hose was shifted, and the heights of water in the boiler at those times, also the temperatures of feed-water. The measurements of the feed-water and the running of the pump were intrusted to one assistant.

Another assistant had charge of the coal accounts, and also took half-hourly observations of the temperatures of the outside air, of the fire-room, steam, pyrometer, water-level, and steam-pressure. This latter observation was taken from the gauge mentioned above, attached just below the stop-valve. A recording gauge was also attached to 
RESULTS OF THE

\begin{tabular}{|c|c|c|c|c|c|c|c|}
\hline Nante of Boiler. & 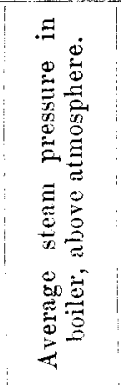 & 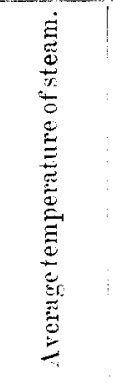 & 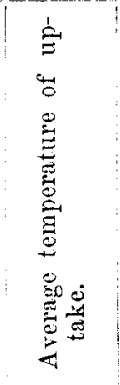 & 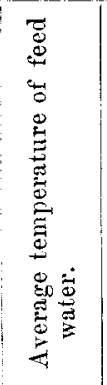 & 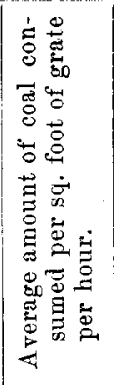 & 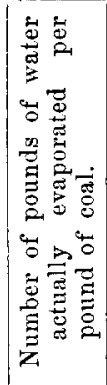 & 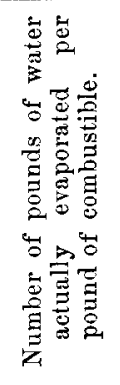 \\
\hline Wiegand,. . & $70 \cdot 029$ & $313 \cdot 17$ & $523 \cdot 81$ & $70 \cdot 80$ & $12 \cdot 32$ & $8 \cdot 219$ & $9 \cdot 097$ \\
\hline Harrison,. . . & $70 \cdot 03$ & $310 \cdot 76^{i}$ & $517 \cdot 50$ & $71 \cdot 16$ & $12 \cdot 30$ & $8 \cdot 036$ & $8 \cdot 785$ \\
\hline Firmenich, . . & $70 \cdot 059$ & $356^{\circ}$ & $415 \cdot 5$ & 68.95 & $11 \cdot 79$ & 8.927 & $9 \cdot 956$ \\
\hline Rogers \& Black, & $70 \cdot 30$ & $|309 \cdot 76|$ & 571 . & $67 \cdot 11$ & & $7 \cdot 266$ & $8 \cdot 059$ \\
\hline Andrews, & $70 \cdot 059$ & $|328 \cdot 47|$ & $419 \cdot 60$ & $65 \cdot 44$ & $8 \cdot 05$ & 7.985 & $8 \cdot 904$ \\
\hline Root, . & $69 \cdot 94$ & $312 \cdot 50$ & 393.33 & 64.59 & $9 \cdot 09$ & $8 \cdot 889$ & $9 \cdot 930$ \\
\hline Kelly,. . . & $69 \cdot 95$ & $310 \cdot 00$ & & $66 \cdot 95$ & 1 & $7 \cdot 858$ & $8 \cdot 636$ \\
\hline Exeter, . . & $70 \cdot 00$ & $308 \cdot 00$ & 429.94 & 68.93 & $9 \cdot 35$ & $7 \cdot 276$ & $8 \cdot 213$ \\
\hline Lowe, . . . . & $70 \cdot 00$ & $309 \cdot 00$ & $332 \cdot 29$ & $66 \cdot 44$ & $6 \cdot 805$ & $8 \cdot 758$ & $9 \cdot 873$ \\
\hline Babcock \& Wilcox & $70 \cdot 00$ & $389 \cdot 06 \mid$ & $295 \cdot 82$ & 63.98 & $9 \cdot 77$ & $8 \cdot 812$ & 8.908 \\
\hline Smith, ${ }^{\mathrm{i}}$. & & & & & & & \\
\hline Galloway, & 70.06 & $310 \cdot 06$ & $303 \cdot 00$ & $|55.95|$ & $8 \cdot 87$ & $8 \cdot 514$ & $9 \cdot 580$ \\
\hline Galloway, ${ }^{\text {ii }}$. & $70 \cdot 12$ & $310 \cdot 06$ & $324 \cdot 62$ & $55 \cdot 12$ & $7 \cdot 269$ & $9 \cdot 182$ & $10 \cdot 069$ \\
\hline Anderson, . & $70 \cdot 00$ & $322 \cdot 75$ & $417 \cdot 00$ & $54 \cdot 00$ & $9 \cdot 747$ & $7 \cdot 918$ & $8 \cdot 727$ \\
\hline Pierce, & $70 \cdot 00$ & 312 & 373.82 & $53 \cdot 20$ & $7 \cdot 99$ & $7 \cdot 419$ & $8 \cdot 336$ \\
\hline
\end{tabular}

i No Table of Results of the Smith Boiler was furnished.

if This test was marle with Bituminous Coal. 
TESTS FOR ECONOMY.

\begin{tabular}{|c|c|c|c|c|c|c|c|c|}
\hline \multirow{2}{*}{ 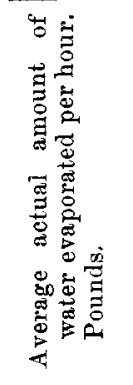 } & \multirow{2}{*}{ 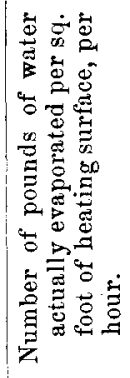 } & \multirow{2}{*}{ 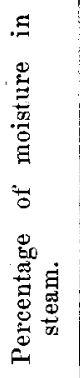 } & \multirow{2}{*}{ 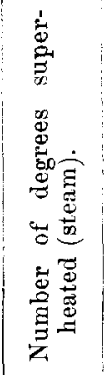 } & \multicolumn{3}{|c|}{$\begin{array}{l}\text { Number of lbs. of satura- } \\
\text { ted steam evaporated at } \\
70 \text { lbs. from } 212^{\circ} \text { equiv- } \\
\text { alent to total heat units } \\
\text { derived from the fuel. }\end{array}$} & \multirow{2}{*}{ 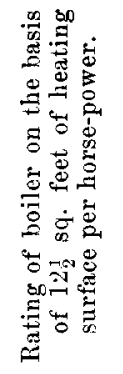 } & \multirow{2}{*}{ 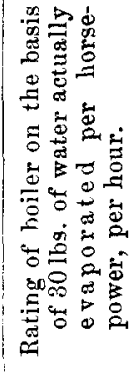 } \\
\hline & & & & 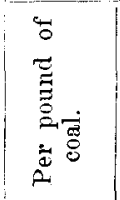 & 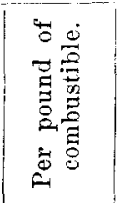 & 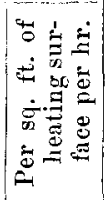 & & \\
\hline $4255 \cdot 36$ & $3 \cdot 14$ & & $13 \cdot 40$ & $9 \cdot 463$ & $10 \cdot 461$ & $|3 \cdot 618|$ & $108 \cdot 40$ & $141 \cdot 85$ \\
\hline 228573 & 2.532 & $1 \cdot 11$ & & $9 \cdot 167$ & 10.022 & $2 \cdot 894$ & $72 \cdot 06$ & $76 \cdot 19$ \\
\hline $1654 \cdot 20$ & 1.533 & & $26 \cdot 70$ & $10 \cdot 340$ & $11 \cdot 530$ & 1.775 & $86 \cdot 31$ & $55 \cdot 14$ \\
\hline 1320.57 & $3 \cdot 30$ & $2 \cdot 68$ & & $8 \cdot 397$ & $9 \cdot 313$ & 3.810 & 31.98 & $44 \cdot 019$ \\
\hline $1183 \cdot 74$ & $2 \cdot 19$ & 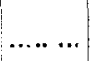 & $52 \cdot 59$ & $9 \cdot 428$ & $10 \cdot 513$ & $2 \cdot 590$ & $43 \cdot 20$ & $39 \cdot 46$ \\
\hline $3393 \cdot 33$ & $2 \cdot 217$ & & $23 \cdot 16$ & $10 \cdot 352$ & 565 & $2 \cdot 485$ & $127 \cdot 20$ & $113 \cdot 11$ \\
\hline $2338 \cdot 56$ & $3 \cdot 532$ & $5 \cdot 97$ & & $9 \cdot 189$ & $10 \cdot 099$ & $4 \cdot 131$ & $52 \cdot 96$ & $7 \cdot 795$ \\
\hline $20 \pm 1 \cdot 70$ & $1 \cdot 338$ & $4 \cdot 63$ & & $8 \cdot 643$ & $9 \cdot 756$ & $|1.589|$ & $122 \cdot 04$ & $68 \cdot 06$ \\
\hline $1341 \cdot 18$ & $1 \cdot 731$ & ....... & $1 \cdot 05$ & $10 \cdot 190$ & $11 \cdot 489$ & $2 \cdot 014$ & $61 \cdot 97$ & $44 \cdot 71$ \\
\hline $3919 \cdot 81$ & $2 \cdot 33$ & 3.24 & & $10 \cdot 211$ & $11 \cdot 489$ & $2 \cdot 701$ & $134 \cdot 40$ & $130 \cdot 66$ \\
\hline & & $\cdots \cdot$ & & & & & & \\
\hline $2945 \cdot 71$ & $3 \cdot 026$ & $0 \cdot 22$ & & $9 \cdot 942$ & $11 \cdot 187$ & $3.533 \mid$ & $77 \cdot 88$ & $98 \cdot 19$ \\
\hline $2603 \cdot 02$ & $2 \cdot 673$ & 0.57 & & $10 \cdot 689$ & $11 \cdot 720$ & $3 \cdot 113$ & $77 \cdot 88$ & 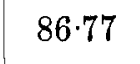 \\
\hline $2778 \cdot 81$ & $2 \cdot 448$ & $\cdots \cdots$ & $14 \cdot 88$ & \begin{tabular}{|l}
$9 \cdot 305$ \\
3
\end{tabular} & $10 \cdot 255$ & $2 \cdot 877$ & $90 \cdot 08$ & $92 \cdot 63$ \\
\hline 61 & $7 \cdot 406$ & 5.53 & & $8 \cdot 738$ & $9 \cdot 818$ & $8 \cdot 714$ & $16 \cdot 03$ & $39 \cdot 48$ \\
\hline
\end{tabular}


the boiler, and served to detect any negligence on the part of the man stationed on top of the boiler to regulate pressure. The barometric pressures given in the logs were not observed in the fire-room. Necessary data were kindly furnished by the Signal Station, U. S. A., and proper corrections were made for level and temperature.

The records of the temperature of steam, as shown in the logs and given by a mercury thermometer, are undoubtedly too low. I found that in certain cases, when a draft would blow over the boiler, the simple fact of covering the stem of the thermometer would cause the mercury to rise 10 or 15 degrees. However, it may be seen that, although the temperatures shown by thermometer fall short of the temperatures indicated by calorimeter, the variations in both sets of records correspond.

\section{COAL AND FIRING.}

The coal used in all the trials was anthracite coal from the Lea Colliery, Wilkesbarre, Pennsylvania, and was the same as was supplied regularly to the Bureau of Machinery; it was nearly all uniform in size; in quality it varied somewhat, as shown in the following table:

\section{Percentage of Refuse from Coal.}

\begin{tabular}{|c|c|c|c|c|c|}
\hline & $\begin{array}{c}\text { Capacity } \\
\text { T'est. }\end{array}$ & $\begin{array}{c}\text { Eeonomy } \\
\text { Test. }\end{array}$ & & $\begin{array}{c}\text { Capacity } \\
\text { Test. }\end{array}$ & $\begin{array}{c}\text { Economy } \\
\text { Test. }\end{array}$ \\
\hline Wiegand, & $8 \cdot 487$ & $9 \cdot 837$ & Exeter, & $9 \cdot 265$ & $11 \cdot 405$ \\
\hline Harrison, & $8 \cdot 369$ & $8 \cdot 526$ & Lowe, . & $10 \cdot 640$ & $11 \cdot 286$ \\
\hline Firmenich, & $8 \cdot 625$ & $10 \cdot 388$ & Babcock \& Wilcox & $7 \cdot 845$ & $10 \cdot 237$ \\
\hline Rogers \& Black, & $8 \cdot 373$ & $9 \cdot 835$ & Galloway, & $11 \cdot 055$ & $11 \cdot 128$ \\
\hline Andrews, & $9 \cdot 428$ & $10 \cdot 319$ & Anderson, & $8 \cdot 684$ & $9 \cdot 261$ \\
\hline $\begin{array}{l}\text { Root, } \\
\text { Kelly, }\end{array}$ & $\begin{array}{l}9 \cdot 6 i 7 \\
8 \cdot(i 7\end{array}$ & $\begin{array}{r}10 \cdot 48 \\
9 \cdot 01\end{array}$ & Pierce, & $8 \cdot 401$ & $11 \cdot 600$ \\
\hline
\end{tabular}

The coal for the trials was by no means selected or picked, but taken as it came, the prevailing object throughout the test being to get at average working conditions.

The two regular trials for economy and capacity were repeated on the Galloway boiler with bituminous coal, that boiler being proportioned for that kind of fuel. The coal used was George's Creek bituminous coal; it was of very fair quality, but necessitated constant attention to the fires, as it ran and caked very freely on the grates.

The firing was left entirely to the judgment of the exhibitors and their men. 


\section{CALORIMETRIC OBSERVATIONS.}

Of the several methods for ascertaining the amount of water carried over with steam from a boiler, the calorimetric investigation of the quality of steam, first applied in 1859 by Prof. G. A. Hirn, is the most simple, the most direct, and the most accurate. At the same time it is so practical that it should certainly come into general use. The principle of this method is to condense a certain weight of steam in a given weight of water contained in a vessel, the temperature of which is thereby increased; the number of heat units imparted to the water (its weight multiplied by the increase in temperature) represents the amount of heat liberated by the steam in condensing, and then cooling down to the temperature at which both the water originally in the tank and that formed by the condensed steam stand at the end of the operation.

In these tests the calorimeter consisted of a plain wooden barrcl, provided with a suitable stirring apparatus, and placed on a platform scale; a drain-pipe was attached to the bottom of the barrel, and provision was made for filling the barrel with water from the hydrant. Into a vertical portion of the steam-pipe of the boiler, and close to and below the stop-valve, was screwed a short horizontal piece of $\frac{3}{4}$-inch pipe, which was screwed in until it touched the opposite side of the steam-pipe. A row of small holes was drilled on one side of the $\frac{3}{4}$-inch nipple, and in attaching it care was taken that the holes should be turned downward, the object of this contrivance being to catch steam from all the portions of the ascending stream in the steam-pipe. To the ${ }_{4}^{3}$-inch nipple was attached a ${ }_{4}^{3}$-inch pipe, felted throughout its length, and running to within a couple of feet of the calorimeter barrel. At the end of this pipe was attached a $\frac{1}{2}$-inch globe valve, and beyond that was fastened a 1 -inch hose about five feet long. The observations were taken every twenty minutes in the following manner: The barrel was filled with water from the hydrant, and the gross weight and the temperature were noted. The globe valve on the $\frac{3}{4}$-inch steam-pipe was opened just enough to puff out all water which might have collected in the pipe; then the end of the hose was dipped in the water in the barrel, and the globe valve opened wide. At the same time a signal was given with a gong for the man on top of the boiler to note the steam-pressure. The water was agitated in the calorimeter barrel so as to insure a thorough distribution of the heat throughout the mass of water. When the 
temperature in the barrel had been raised sufficiently, the globe valve was closed; the signal was repeated for the man on top of the boiler to note the steam-pressure again, and the temperature of the water in the barrel was carefully observed; then, after taking the hose out of the water, and letting drip from it into the barrel all water which might have been lifted with it, the final gross weight was taken, the increase in weight representing the steam (with water primed, if any) brought in to the barrel.

During the progress of a calorimetric observation the man on the top of the boiler was not allowed to touch the stop-valve, in order to prevent changing the conditions of steam.

The duration of the calorimetric experiments varied somewhat. It was attempted as a rule to reach a final temperature in the barrel as many degrees above the temperature of the surrounding atmosphere as the initial temperature was below, the object being to compensate for loss and absorption of heat through the surface.

All things being equal, the duration of the experiment was governed by the quality of steam, as the hotter the steam the less time it would take to heat the contents of the barrel. This may seem useless to mention, still, it showed the sensitiveness of the apparatus.

The calorimeter data are given in the logs. The weight of the barrel is also given; it is the mean of two weighings at the beginning and the end of the trial. An allowance has been made, in computing the results, for the iron stirring apparatus in the barrel, which has to be heated every time, with the water. The weight of the stirrer, multiplied by the specific heat of iron, has been added in all cases to the net amount of water heated.

A New Washing Fluid.-Beat 1 kilogramme of soap, with a little water, into a paste, warm it moderately, and incorporate it, by thorough stirring, into 45 litres of water at a temperature of about $30^{\circ} \mathrm{C} .\left(86^{\circ} \mathrm{F}\right.$.), to which 1 tablespoonful of oil of turpentine and 2 tablespoonfuls of ammonia have been added. The articles to be washed are to be soaked in this mixture for two hours, and then washed as usual. The fluid can be rewarmed and used a second time, by adding more turpentine and ammonia. The process is said to be time, labor and money-saving, much less soap and rubbing being needed, and the wear of the clothes is greatly diminished.Neueste Erfind. u. Erfahr.; Pap. Zeit., May 3. 